\title{
A Norma de Proteção de Civis nas Operações de Paz da ONU: os mandatos robustos
}

\section{da década de 2000}

The Civilian Protection Norm in the United Nations Peace Operations: robust mandates in the 2000s decade

Juliana de Paula Bigatão1

\begin{abstract}
RESUMO
0 artigo discute de que forma as operações de paz da ONU incorporaram a norma de proteção de civis e quais foram as implicações da autorização de mandatos robustos para os princípios básicos dessas operações. 0 argumento central é que estes mandatos não alteram a essência das operações de paz, dados os limites que o princípio do consentimento impõe às ações dos peacekeepers.
\end{abstract}

Palavras-chave: Nações Unidas; Proteção de Civis; Mandatos robustos.

\begin{abstract}
The paper discusses how UN peace operations changed to reflect the normative debate about the centrality of human protection and what were the implications of robust mandates to basic peacekeeping principles. It is argued that although robust mandates authorized peacekeepers to protect civilians under imminent threat of physical violence, the principle of consent limited their ability to fully carry out its mandated tasks.
\end{abstract}

Keywords: United Nations; Civilian Protection; Robust Mandate.

\section{INTRODUÇÃO}

O estudo da evolução das operações de paz das Nações Unidas (ONU) representa um esforço para compreender as reações dessa organização frente às transformações do cenário bélico que, longe de representar um processo evolutivo linear, traz à tona diferentes formas de enfrentamento entre Estados, comunidades e indivíduos. É possível observar as mudanças no perfil das operações de paz a partir da constatação de que as reduzidas operações de monitoramento de tréguas entre Estados, típicas das primeiras

\footnotetext{
1 Doutora em Relações Internacionais pelo Programa San Tiago Dantas (UNESP/UNICAMP/PUC-SP). Coordenadora e Docente do Curso de Graduação de Relações Internacionais da Universidade de Ribeirão Preto (UNAERP). Foi bolsista CAPES durante o período de doutoramento.
} 
experiências de mediação da ONU nas décadas de 1940 e 1950, diferenciam-se consideravelmente daquelas destinadas a administrar territórios e prover assistência humanitária. Também pelo fato de que os primeiros peacekeepers ${ }^{2}$ eram majoritariamente observadores desarmados e, a partir do final da década de 1980, uma gama maior de atores passou a compor as missões, como policiais e agentes humanitários, além dos militares que passaram a ter autorização para portar armamento e usar a força de maneira mais incisiva.

Na década de 1990, as operações de paz da ONU passaram por um movimento de expansão e retração, tendo como ponto de inflexão os massacres de civis sob os olhares dos peacekeepers na Bósnia e em Ruanda e a incapacidade da organização em responder adequadamente à crise humanitária na Somália, fatos ocorridos entre 1993 e 1995. Entre 1991-1995, o Conselho de Segurança das Nações Unidas (CSNU) autorizou 21 operações de paz, enquanto entre 1996 e 1999 o número caiu para 14 novas missões, a maioria em territórios que já contavam com a presença dos peacekeepers ${ }^{3}$.

Conforme avalia Fréchette (2012), o massacre de civis sob os olhares dos peacekeepers na Bósnia, principalmente em Srebrenica, e em Ruanda trouxe à tona, da maneira mais trágica possível, as limitações das operações de paz da ONU. 0 editorial do jornal The New York Times de 08/01/1995, avaliava:

\begin{abstract}
Repensar e recuar estão em pauta... Deve haver um retorno em direção a objetivos mais limitados como o monitoramento de cessar-fogo. As operações de paz da ONU fazem o que podem melhor fazer. Não faz sentido continuar erodindo sua credibilidade [da $\mathrm{ONU}$ ] ao pedir que faça o que não pode. ('The future of peacekeeping', editorial, New York Times, 8 Jan. 1995 apud FINDLAY, 2002, p. 315; tradução nossa).
\end{abstract}

As críticas a respeito da credibilidade das operações de paz incitaram um processo de revisão que buscou refletir sobre as limitações destes mecanismos de resolução de conflitos e também formular novas diretrizes para evitar a repetição dos fracassos. Em 1999 foram divulgados dois relatórios sobre os problemas confrontados pelas operações na Bósnia e em Ruanda, respectivamente The fall of Srebrenica (ONU, A/54/549, 1999a) e The Report of the Independent Inquiry into the Actions of the United

\footnotetext{
${ }^{2}$ Adota-se neste artigo alguns termos em inglês por se entender que a tradução não é satisfatória.

3 Das 14 novas missões do período 1996-1999, apenas seis foram dirigidas a países que não contaram com a presença anterior de operação de paz da ONU. Dados disponíveis em <http://www.un.org/en/peacekeeping/documents/operationslist.pdf> Acesso em 23/01/2015.
}

Conjuntura Global, vol. 5 n. 3, set./dez, 2016, p. 460 - 483 
Nations during the 1994 Genocide in Rwanda (ONU, S/1999/1257, 1999b); e em 2000 o então Secretário-Geral Kofi Annan convocou um grupo de especialistas para elaborar uma ampla revisão das operações de paz da ONU, publicada sob o título Report of the Panel on United Nations Peace Operations (ONU, A/55/305, 2000), mais conhecido como Relatório Brahimi, em referência ao presidente do painel, o ex-Ministro das Relações Exteriores da Argélia, Lakhdar Brahimi.

Uma das alterações mais significativas nas operações aprovadas no período 20012010 foi a autorização de mandatos robustos para a proteção de civis. Este artigo propõe a discussão sobre a emergência da norma para a proteção de civis no panorama da ONU e a análise das implicações da centralidade da proteção humana para os princípios básicos que constituem a essência das operações de paz - consentimento, imparcialidade e uso da força restrito à autodefesa.

Tomam-se, como materiais de pesquisa, os relatórios de comissões internas e independentes da ONU, as resoluções do CSNU que autorizam as operações de paz e a revisão da literatura pertinente ao tema. $O$ argumento central é que os mandatos robustos não alteraram a essência das operações de paz e não as transformaram em operações de guerra, dados os limites impostos às ações dos peacekeepers. Muitos dos dilemas enfrentados nos anos 2000 foram semelhantes àqueles verificados na década de 1990, inseridos na problemática que contrapõe as missões multidimensionais com mandatos robustos, o princípio do consentimento das partes e as limitações quanto ao uso da força.

Neste artigo, o termo "operações de paz" refere-se a todos os tipos de missões autorizadas pelo CSNU e gerenciadas pelo Departamento de Operações de Paz da ONU (DPKO, da sigla em inglês). Tais operações empregam, de forma individual ou combinada, as técnicas de resolução de conflitos descritas nos documentos "Uma Agenda para a Paz" (1992) e "Suplemento de Uma Agenda para a Paz" (1995): peacemaking, peacekeeping, peacebuilding e peace enforcement. A diferenciação entre essas técnicas oferece um marco analítico para o estudo das operações de paz; porém, na prática, a atuação da ONU implica na inter-relação de tais categorias, sendo o termo peacekeeping o mais abrangente para 
caracterizar a prática das operações de paz, mesmo que envolva outras técnicas previstas na Agenda. 4

É importante destacar, também, que a ONU não responde aos conflitos mediante a demanda por sua atuação. Uma combinação de fatores influencia a autorização das operações de paz pelo CSNU, entre eles a oferta de determinadas capacidades ao seu dispor (forças militares, policiais e civis, recursos financeiros e materiais); a existência de determinadas normas que justifiquem a intervenção frente aos princípios da soberania e independência dos Estados; as condições apresentadas pelos grupos em conflito; além da vontade institucional e dos Estados membros para assumir responsabilidades e cumprir seus propósitos fundamentais. Mesmo quando tais condições são observadas e o CSNU autoriza uma operação de paz, o modelo de intervenção resultante deste intrincado processo pode descolar-se da concepção de paz disseminada pela ONU, pois a tradução desta concepção em um mandato é condicionada pelo equacionamento de diferentes variáveis.

As decisões do CSNU não partem de avaliações técnicas a respeito dos conflitos e das possibilidades de mediação, mas de um intrincado cálculo político que equaciona interesses políticos individuais e coletivos, referentes às políticas de cada Estado membro do CSNU - principalmente os cinco permanentes - e à função de uma organização internacional que possui como finalidade a manutenção da paz e segurança internacionais. Além disso, a escolha do modelo de intervenção relaciona-se com a lógica que orienta as decisões dos Estados-membros para arcarem com os custos políticos e financeiros das operações de paz, sejam os atores responsáveis por aprovar as missões ou aqueles que disponibilizam os recursos humanos e materiais para operacionalizá-las.

Assim, com a finalidade de apresentar a análise sobre a incorporação da norma de proteção de civis no âmbito das operações de paz e a forma como CSNU operacionalizou essa norma nos chamados mandatos robustos, este artigo divide-se em duas seções. A primeira faz uma retomada do desenvolvimento institucional das operações de paz na década de 2000, com ênfase na discussão da centralidade da proteção humana frente aos

\footnotetext{
${ }^{4}$ A respeito da literatura que discute o envio de operações de paz ao terreno, consultar: FORTNA, V. P. Does Peacekeeping Work? Shaping Belligerents'Choices After Civil War. Princeton: Princeton University Press, 2008; e PARIS, R. At War's End: Building Peace After Civil Conflict. Nova Iorque: Cambridge, 2004.
} 
princípios básicos que constituem a essência das operações de paz - consentimento, imparcialidade e uso da força restrito à autodefesa. A segunda parte analisa a inserção da proteção de civis nos mandatos autorizados pelo CSNU na década de 2000 e discute alguns casos que exemplificam a tensão existente entre os mandatos robustos e os princípios essenciais das missões da ONU.

\section{O DESENVOLVIMENTO INSTITUCIONAL DAS OPERAÇÕES DE PAZ DA ONU: AS PRINCIPAIS MUDANÇAS NA DÉCADA DE 2000}

A expansão do número de novas operações de paz e da complexidade dos mandatos que o CSNU delegou aos peacekeepers na primeira metade da década de 1990 revelou diversas lacunas na forma como a ONU estava respondendo aos conflitos internacionais, prioritariamente às guerras civis. Embora algumas missões tenham atingido seus objetivos e contribuído para uma avaliação positiva dos processos de reconciliação nacional, como nos casos de El Salvador e da Namíbia, as experiências que mais marcaram a imagem das operações de paz naquele período passaram-se nas frustrantes missões na ex-Iugoslávia, na Somália e em Ruanda.

Nos episódios mais dramáticos, os peacekeepers assistiram ao massacre de milhares de pessoas, sem possuir mandato ou instrumentos para agir. Em Ruanda, mais de 750 mil pessoas foram mortas entre os meses de abril e junho de 1994 e a força "neutra" multinacional da ONU destacada no país em outubro de 1993, com um mandato restrito ao uso da força em autodefesa, não se mostrou minimamente suficiente para evitar o ocorrido. Na ex-Iugoslávia, a suposta "área protegida" da ONU em Srebrenica foi palco do assassinato de mais de 7.500 civis, em julho de 1995, sob os olhares de um modesto contingente de peacekeepers holandeses. (BELLAMY et. al, 2004).

Em 1995, o "Suplemento da Agenda para a Paz" (ONU, A/50/60, 1995) propôs a flexibilização dos princípios tradicionais das missões, com base na justificativa de que impediam uma ação incisiva dos peacekeepers frente aos indivíduos e grupos beligerantes que tomavam a população civil como alvo de violência. A noção de peace-enforcement, que não apareceu na "Agenda" (1992), foi adicionada a seu "Suplemento" para referir-se a medidas coercitivas que não contavam com o consentimento de todas as partes em conflito. No entanto, o documento enfatizou que, naquele momento, o CSNU e o 
Secretariado não possuíam capacidade para destacar, comandar e gerenciar operações de enforcement, a não ser em escala bastante limitada.

A partir de 1997, com a nomeação de Kofi Annan à Secretaria Geral, iniciou-se um movimento mais direcionado para a revisão das missões de paz, com a produção de dois relatórios críticos, um sobre a ex-Iugoslávia e outro sobre Ruanda. 0 novo Secretário-Geral havia acompanhado de perto o tortuoso caminho dos peacekeepers, primeiro na condição de diretor do DPKO, desde 1993, e depois como Representante Especial do SecretárioGeral para a Iugoslávia, entre 1995 e 1996.

O relatório sobre a missão na ex-Iugoslávia, elaborado pelo Secretariado a pedido do CSNU, foi publicado em novembro de 1999 com o título The fall of Srebrenica. Segundo o documento, o massacre de civis na suposta área protegida pela ONU em Srebrenica deixou a lição de que a ONU não deveria enviar peacekeepers a conflitos em andamento nos quais inexistia um processo de diálogo político que garantisse um cessar fogo ou acordo de paz. Ponderando sobre a tensão entre o uso da força e a imparcialidade, apontou-se que todos os meios necessários devem ser utilizados para impedir a perseguição e o massacre de civis nas zonas de conflito. (ONU, A/54/549, 1999a).

Publicado também ao final de 1999, o relatório sobre Ruanda (The Report of the Independent Inquiry into the Actions of the United Nations during the 1994 Genocide in Rwanda), elaborado sob a direção do ex-Primeiro Ministro sueco Ingmar Carlsson, explicitou que a falta de recursos e de comprometimento político por parte dos Estadosmembros resultaram na inabilidade da missão em prevenir o genocídio, apontando que o sistema ONU falhou como um todo (ONU, S/1999/1257, 1999b). Na avaliação de Fréchette (2012), o documentou foi bastante explícito sobre a necessidade de repensar os princípios tradicionais das missões de paz frente à proteção de civis, expressando que não pode haver neutralidade face a um genocídio, nem imparcialidade frente a uma campanha de extermínio de determinado grupo.

Segundo Malone e Thakur (2001), em março de 2000, Annan aproveitou as repercussões dos relatórios sobre Ruanda e Srebrenica para convocar um painel de especialistas e encomendar uma revisão mais abrangente sobre as missões de paz, desta vez buscando recomendações concretas para fortalecer a capacidade da ONU em responder a crises. 0 momento era propício não somente pelo engajamento pessoal do Secretário-Geral no processo de revisão e no âmbito mais amplo no debate sobre a 
renovação do sistema $\mathrm{ONU}$, mas, também, em virtude das dificuldades enfrentadas na missão de paz então vigente em Serra Leoa e na definição do papel da ONU na administração interina do Kosovo após o bombardeio da OTAN na região.

O Painel sobre as Operações de Paz da ONU, composto por dez especialistas com relevante experiência nas áreas diplomática, militar e humanitária e presidido por Lakhdar Brahimi, ex-primeiro Ministro da Argélia e ex-Representante da ONU em missões no Haiti, África do Sul, Zaire, Iêmen e Afeganistão, apresentou o relatório final ao Secretário-Geral em 17 de Agosto de 2000. De acordo com Gray (2001), o Relatório Brahimi (2000), como ficou conhecido o documento final, norteou parte das discussões da Cúpula do Milênio do CSNU, em 07/09/2000, quando a resolução 1318/2000 endossou por unanimidade o documento.

Na avaliação do grupo de especialistas do Painel, algumas missões da década de 1990 enviadas para países que vivenciavam guerras civis foram concebidas da seguinte forma: no primeiro momento, os peacekeepers atuariam na garantia de um ambiente seguro e sua presença impactaria positivamente no controle da violência; enquanto os peacemakers promoveriam o diálogo entre as principais partes em conflito para negociar um acordo político. Após atingir tais condições - estabilidade e acordo de paz - os peacebuilders voltar-se-iam à promoção de atividades que criassem condições para o estabelecimento de uma paz sustentável. Todavia, o grupo de especialistas constatou que, na prática, alguns dos grupos armados possuíam incentivos políticos e econômicos para continuar engajados, sem perspectivas para negociar acordos de paz ou mesmo respeitar a presença dos peacekeepers. Concluiu-se que este último fator era determinante para que as missões atingissem seus objetivos, sendo que muitas não foram capazes de garantir a estabilização do conflito, nem ao menos proteger a população, sendo encerradas antes mesmo de se alcançar a etapa de consolidação da paz.

Tomando como base o diagnóstico supracitado, o Relatório Brahimi (2000) apontou que as respostas da ONU aos conflitos deveriam ser repensadas e estabeleceu que "há muitas tarefas que as forças de paz da ONU não devem ser requisitadas a assumir e muitos lugares em que não devem ir". Caso o CSNU decidisse pela aprovação de uma missão de paz, os peacekeepers "devem estar preparados para confrontar as forças persistentes da guerra e da violência com habilidade e determinação para derrotá-las". (ONU, A/55/305, p. viii; tradução nossa). 
Imprimiu-se no documento a noção de que as operações de paz não são instrumentos adequados para responder a todos os tipos de conflito, ou pelo menos a todas as etapas de um conflito. Ao condicionar o envio das missões à existência de um engajamento prévio das partes em conflito no processo negociador, evidenciou-se que o princípio do consentimento das partes manteria sua centralidade na tomada de decisão quanto à aprovação de novas missões de paz, retomando, assim, o que foi chamado no início deste artigo como "essência" das operações de paz.

Em documentos posteriores, o Secretariado e os Estados-membros deram maior ênfase às normas, valores e princípios que deveriam orientar a concepção e a prática das operações de paz, priorizando o debate sobre "quando intervir" e "com qual finalidade" e, dessa forma, complementando as discussões do Relatório Brahimi (2000).

O High-level Panel on Threats, Challenges and Change [A/59/565], convocado por Annan em novembro de 2003, teve como objetivo avaliar o enquadramento da segurança coletiva no novo século, com base no contexto marcado por: I. A invasão unilateral dos Estados Unidos no Iraque, sem o aval do CSNU, a qual impôs muitas dúvidas a respeito da centralidade do órgão e das circunstâncias em que o sistema de segurança coletiva poderia ser acionado; II. A necessidade de definir a natureza das ameaças que atingiam principalmente os países menos desenvolvidos e as formas de enfrentamento; III. A aproximação das cúpulas que marcariam os 60 anos da ONU em 2005, abrindo espaço para as discussões sobre a reforma e adaptação da organização à ordem mundial contemporânea. (EVANS, 2004).

O Relatório final, apresentado à Assembleia Geral em 02/12/2004 com o título $A$ more secure world: our shared responsibility, foi dividido em quatro partes. Considerando o objetivo deste artigo, destacam-se duas delas. Na primeira -Towards a new security consensus - abordou-se a natureza das ameaças à segurança estatal e humana, elevadas ao mesmo patamar de importância, apresentando como elemento fundamental a indivisibilidade do trinômio segurança, desenvolvimento econômico e liberdade. 0 Painel reconheceu que, sessenta anos após a criação da ONU, as ameaças à segurança não mais se circunscreviam às guerras entre Estados, mas se expandiram de forma a abarcar a violência que se manifesta no interior dos países; a pobreza, as doenças infectocontagiosas e a degradação ambiental; as armas nucleares, químicas e biológicas; assim como o terrorismo e o crime organizado. 
Já na terceira parte do Relatório, os especialistas trataram da relação entre a segurança coletiva e o uso da força. Para tanto, mencionaram que o Artigo 51 da Carta da ONU (1945), abarcado sob a égide do Capítulo VII, é suficiente para orientar situações em que: I. Um Estado reivindica agir em legítima defesa; II. Um Estado representa uma ameaça a outros; III. Há uma ameaça interna que se relaciona com a responsabilidade do Estado de proteger sua própria população. Ao delimitar a quais ameaças o CSNU deveria responder, o documento ressaltou que alguns fenômenos classificados como ameaças como a pobreza, as doenças e a degradação ambiental - deveriam ser enfrentadas por outros meios, enfatizando a importância dos programas de desenvolvimento e não o uso da força.

Especificamente sobre as operações de paz, o High-level Panel destacou que, embora a ONU tenha lançado e disseminado a noção de segurança humana, mostrou-se pouco preparada para provê-la. Nos momentos mais dramáticos, não foi capaz de prevenir atos de genocídio e limpeza étnica. Assim como argumentado no Relatório Brahimi (2000), mais uma vez ganhou destaque nas justificativas para as falhas que ocorreram na década de 1990 o fato de que um sistema de segurança coletiva efetivo e eficiente demanda um verdadeiro comprometimento dos Estados-membros da ONU para que sejam oferecidas capacidades militares suficientes às demandas das operações de paz.

Comparado a outros documentos da ONU, o High-level Panel aprofundou a discussão a respeito da doutrina do emprego da força por parte dos peacekeepers, sugerindo que mesmo as missões direcionadas a conflitos considerados de baixo risco (quando se considera, por exemplo, a adesão dos beligerantes aos acordos de paz) deveriam ser respaldadas pelo Capítulo VII. Tal medida foi justificada como necessária para garantir o preparo dos peacekeepers para proteger os civis, caso grupos armados ou o próprio governo anfitrião desrespeitassem os termos acordados. De forma mais enfática do que apresentado em documentos anteriores, o High-level Panel expressou que os acordos de paz firmados com governos ou grupos rebeldes envolvidos em graves violações aos direitos humanos não possuem validade e não devem ser aceitos como instrumento de pacificação ou garantia do consentimento das partes. Neste caso, recomendou-se que a ONU interfira de forma coercitiva para deter os grupos hostis e garantir a proteção dos civis e dos agentes humanitários. 
Dois aspectos foram apontados como os "verdadeiros desafios" das missões de paz: garantir que elas tenham “(a) mandato apropriado, claro e bem definido, aplicável às circunstâncias diversas que possam ser razoavelmente previstas, e (b) todos os recursos necessários para implementar o mandato integralmente" (ONU, A/59/565, 2004, par. 214, tradução nossa). 0 documento apresentou que "as operações de paz falham quando os recursos e estratégias não são proporcionais ao desafio a que se propõem" (ONU, A/59/565, 2004, par. 222; tradução nossa).

No ano seguinte à publicação do relatório $A$ more secure world: our shared responsibility, mais um passo foi dado na discussão sobre as normas para a proteção humana em cenários de conflito. Na Cúpula Mundial de 2005, realizada entre os dias 14 e 16/09, mais de 150 Estados-membros participaram de debates sobre as medidas que deveriam ser tomadas para garantir a consecução dos Objetivos de Desenvolvimento do Milênio, priorizando quatro áreas: desenvolvimento; paz e segurança coletiva; direitos humanos e o Estado de Direito; e fortalecimento da ONU.

A resolução final da Cúpula (A/RES/60/1) adotou o princípio da Responsabilidade de Proteger populações de genocídio, crimes de guerra, limpeza étnica e crimes contra a humanidade. Apresentado em 2001 com a publicação do relatório da “Comissão Internacional sobre Intervenção e Soberania dos Estados” (ICISS), intitulado "A Responsabilidade de Proteger", tal princípio estabelece que

(...) os Estados soberanos possuem a responsabilidade de proteger seus próprios cidadãos das catástrofes que podem ser evitadas - assassinatos em massa, violações sistemáticas [dos direitos humanos] e inanição - mas se não querem ou não podem fazê-lo, essa responsabilidade recai sobre a comunidade de Estados. (Informe de la Comisión Internacional sobre Intervención y Soberanía de los Estados. La responsabilidad de proteger. Deciembre de 2001; tradução nossa).

A ICISS foi estabelecida pelo governo canadense mediante questionamentos do Secretário-Geral Kofi Annan expostos na Cúpula do Milênio (2000): como responder a violações sistemáticas aos direitos humanos, como as ocorridas em Ruanda e Srebrenica, sem recorrer à prática da intervenção humanitária? (EVANS, 2012). Naquele momento, o debate em torno deste tipo de intervenção colocava em evidência que a articulação entre a segurança e os direitos humanos estava circundada pela seletividade e politização das respostas às crises humanitárias e que alguns países utilizavam o rótulo da "intervenção humanitária" para a realização de interesses individuais. A própria ONU evitava que a expressão "intervenção humanitária" aparecesse em seus documentos e declarações 
oficiais e buscava desenvolver normas, princípios e procedimentos que regulassem as respostas aos casos de violações aos direitos humanos em larga escala. 0 princípio da Responsabilidade de Proteger foi, então, apresentado com o intuito de orientar um mínimo consenso internacional não apenas para reagir, mas também para reconstruir e prevenir quatro situações específicas: genocídio, limpeza étnica, crimes de guerra e crimes contra a humanidade.

Embora o High-level Panel on Threats, Challenges and Change (2004) e o relatório In larger freedom: towards development, security and human rights for all (2005) tenham se referido a alguns aspectos normativos da Responsabilidade de Proteger, a Resolução da Cúpula Mundial de 2005 adotou formalmente o princípio no ordenamento da ONU, ao estabelecer que a comunidade internacional possui a responsabilidade de empregar os meios apropriados - diplomáticos, humanitários e outros meios pacíficos - para auxiliar a proteção das populações contra genocídio, crimes de guerra, limpeza étnica e crimes contra a humanidade, de acordo com os Capítulos VI e VIII da Carta de São Francisco (1945). Para isso, estipulou-se que o CSNU deve decidir, caso a caso, e se necessário em parceria com as organizações regionais, a forma de responder a situações em que as autoridades nacionais falham em proteger os civis dos quatro crimes supracitados, inclusive acionando o Capítulo VII da Carta. (A/RES/60/1; par. 138-139).

No ano seguinte, o princípio da Responsabilidade de Proteger foi endossado no nível mais alto da tomada de decisão da ONU, quando a Resolução 1674 do CSNU, de 28 de abril de 2006, reafirmou os parágrafos 138 e 139 do documento final da Cúpula de 2005 relativos à Responsabilidade de Proteger. O CSNU adotou, também, resoluções específicas sobre a proteção de mulheres, crianças e agentes humanitários em zonas de conflito.

O debate sobre a Responsabilidade de Proteger avançou no sistema ONU a partir da necessidade de se definir de que forma o princípio seria traduzido em ações concretas e se existiria vontade política e preparo institucional para isso. Em 2009, o SecretárioGeral Ban Ki-moon aprofundou o debate ao apresentar os três pilares da Responsabilidade de Proteger: I. A responsabilidade primária do Estado de proteger sua população do genocídio, crimes de guerra, limpeza étnica e crimes contra a humanidade; II. O comprometimento da comunidade internacional em auxiliar os Estados a cumprirem a responsabilidade do pilar I; III. A responsabilidade dos Estados-membros de responder 
coletivamente, em tempo hábil e de forma decisiva, às situações em que o Estado falha em prover a proteção.

Para Ban Ki-moon, o CSNU manteria sua centralidade no processo de tomada de decisão caso fosse necessário deliberar sobre a resposta da ONU aos casos abarcados no pilar III. Além disso, o Secretário-Geral argumentou que a melhor forma de persuadir os Estados a cumprirem sua responsabilidade de proteger seria desenvolver estratégias, processos, ferramentas e práticas institucionais que possibilitassem, em última instância, a aplicação do terceiro pilar. (A/63/677).

As resoluções do CSNU 1674 (2006) e 1894 (2009) sobre a proteção de civis em zonas de conflito reafirmaram a Responsabilidade de Proteger. Porém, estes documentos não estabeleceram as diretrizes e doutrina que deveriam orientar a implementação do princípio. Neste caso, é importante enfatizar que as operações de paz pautadas no consentimento das partes em conflito não são os instrumentos adequados para operacionalizar o princípio da responsabilidade de proteger quando se trata de atrocidades perpetradas por governos contra suas próprias populações. Isso porque é muito improvável que as autoridades governamentais endossem ações coercitivas de atores internacionais contra si mesmas.

O documento United Nations Peacekeeping Operations: Principles and Guidelines, conhecido como Doutrina Capstone, publicado em 2008 pelo DPKO em parceria com o Departamento de Apoio em Campo, avançou na discussão sobre o emprego da força nas operações de paz, não apenas referente ao princípio da Responsabilidade de Proteger, mas a partir de uma abordagem mais ampla:

As operações de manutenção da paz podem também utilizar a força no nível tático, com a autorização do Conselho de Segurança, para defender a si mesmas e seus mandatos, particularmente em situações nas quais o Estado é incapaz de prover segurança e manter a ordem pública. [...] embora a linha entre a manutenção da paz "robusta" e a imposição da paz possa às vezes parecer nebulosa, há importantes diferenças entre elas. Enquanto a manutenção da paz robusta envolve o uso da força no nível tático com o consentimento das autoridades anfitriãs e/ou das principais partes envolvidas no conflito, a imposição da paz pode envolver o uso da força no nível estratégico ou internacional, o que normalmente é proibido aos Estados-membros, de acordo com Artigo 2(4) da Carta, ao menos que autorizado pelo Conselho de Segurança. (ONU, Peacekeeping Operations: Principles and Guidelines, 2008, p. 19; tradução nossa).

Em nosso entendimento, a Doutrina Capstone estabelece uma importante distinção entre as operações de paz e outras intervenções que podem ser autorizadas pelo 
CSNU. 0 primeiro caso - "manutenção da paz robusta" - se refere a operações de paz autorizadas com o consentimento das partes e respaldadas pelo Capítulo VII da Carta. 0 acionamento do Capítulo VII no âmbito das operações de paz autoriza uso da força, porém dentro das circunstâncias delimitadas pelo CSNU, as quais geralmente aparecem nas resoluções do órgão nos termos de uso da força em autodefesa, para a defesa do mandato e dos integrantes da missão. 0 segundo caso - "imposição da paz - aponta para intervenções que no sentido estrito não seriam classificadas como operações de paz, pois, além de autorizar o uso da força, não contam com o consentimento das partes. Embora a questão do consentimento tenha sido flexibilizada ao longo da evolução das operações de paz, o próprio Relatório Brahimi estabelece que este é um aspecto central na decisão de se instituir novas missões.

Desta forma, é possível afirmar que os debates a respeito da centralidade da proteção humana no ordenamento da ONU e a adoção de normas para a proteção de civis por parte do CSNU, principalmente na década de 2000, representaram um esforço para adaptar as respostas da organização às características dos conflitos contemporâneos e evitar a repetição das atrocidades ocorridas nas missões de meados da década de 1990. Não obstante, estes debates incitam muitos questionamentos a respeito da operacionalização da base normativa da proteção de civis, particularmente no que se refere à aplicação da força e ao consentimento das partes em conflito. Na próxima seção, discute-se de que maneira a norma de proteção de civis foi implementada no âmbito das operações de paz da ONU na década de 2000.

\section{A PROTEÇÃO DE CIVIS NOS MANDATOS DA DÉCADA DE 2000}

Segundo Hultman (2013), desde o momento em que a mudança no padrão de conflitos tomou a agenda da ONU, a partir da constatação do predomínio das guerras intraestatais que afetavam diretamente os civis, a organização passou a preocupar-se com a proteção humana. 0 então Secretário-Geral Javier Pérez de Cuéllar (1982-1991), ao tratar do impacto dos conflitos para a população civil, declarou em 1991: “O que está envolvido não é o direito de intervenção, mas a obrigação coletiva dos Estados em levar alívio e reparação às emergências de direitos humanos." (HULTMAN, 2013, p. 61, tradução nossa). 
No entanto, naquele momento não havia consenso a respeito da obrigação coletiva dos membros da ONU de agir decisivamente para colocar fim às atrocidades cometidas contra os civis em áreas de conflito. Somente em meados da década de 1990 o tema ganhou destaque, principalmente após os desastres humanitários que envolveram episódios de genocídio e limpeza étnica em que civis foram mortos aos olhos dos peacekeepers, gerando promessas de que a ONU nunca mais permitiria a repetição de tais atos. (HULTMAN, 2014)

Em discurso na Universidade de Oxford em 02/02/2011, Ban Ki-moon argumentou que a ONU adentrou o século XXI carregando um legado de trágicos eventos que impulsionou a inserção da proteção humana no centro dos princípios da organização, tornando-se, também, a marca de sua gestão na Secretaria Geral. Para ele, a proteção humana é um instrumento chave das operações de paz, principalmente quando a ONU está no controle de ameaças iminentes à sobrevivência de indivíduos e grupos em contextos de conflito e crises humanitárias. O Secretário-Geral enfatizou que o CSNU tem adotado uma postura responsável ao autorizar mandatos mais amplos e robustos, colocando a proteção de civis em conflitos armados no topo das prioridades operacionais da agenda de paz e segurança da organização. (KI-MOON, 2011).

Consoante com a Doutrina Capstone (2008), segundo a qual as decisões do CSNU refletem o debate normativo mais amplo que molda o ambiente internacional, os mandatos aprovados na década de 2000 estavam alinhados à norma da proteção humana, representando uma nova abordagem sobre o assunto por parte do órgão, bastante influenciada pela insistência do Secretariado em priorizar a temática. (BELLAMY; WILLIAMS, 2011)

Embora esteja inserido no quadro mais amplo em que o CSNU endossou o princípio da Responsabilidade de Proteger, o debate sobre a proteção humana é anterior e apareceu pela primeira vez no panorama das missões de paz no final da década de 1990 . Na Resolução 1265 (1999), o CSNU reconheceu que os civis constituíam a maioria das baixas nos conflitos armados e que cada vez mais tornavam-se alvos de grupos rebeldes. Além de condenar estes atos, o órgão expressou sua disposição para responder a eles e atribuir aos mandatos das missões de paz elementos que as tornassem mais preparadas para lidar com os impactos dos conflitos sobre os civis. Um mês depois, a resolução 1270 
(1999) autorizou a Missão das Nações Unidas em Serra Leoa (UNAMSIL) nos seguintes termos:

De acordo com o Capítulo VII da Carta das Nações Unidas, decide-se que no cumprimento de seu mandato, a UNAMSIL deve tomar toda ação necessária para garantir a segurança e liberdade de movimento de seu pessoal e, dentro de suas capacidades e área de atuação, proporcionar a proteção de civis sob a iminente ameaça de violência física, levando em consideração as responsabilidades do governo de Serra Leoa (...). (S/RES/1270, 1999, par. 14. United Nations Security Council, 22 October 1999; tradução nossa)

A Resolução citada inaugurou um período em que uma série de mandatos atribuiu explicitamente aos peacekeepers a responsabilidade de proteger os civis sob ameaça iminente contra sua integridade física. Conquanto seja necessário tomar cuidado em se referir ao CSNU como um ator unitário, em razão da diversidade de interesses dos Estados que o compõe, neste caso, a proteção de civis foi um tema consensual entre seus membros, pois os mandatos aprovados entre 1999 e 2010, que incluíam a proteção de civis, foram adotados por unanimidade. De acordo com o representante diplomático argentino presente na sessão que aprovou a Resolução 1270 (1999), esta introduziu uma nova dimensão política, legal e moral às missões de paz. (HULTMAN, 2013)

No ano seguinte, o Relatório Brahimi (2000) estabeleceu que

Os peacekeepers das Nações Unidas - tropas e policiais - que testemunharem violência contra civis devem presumidamente serem autorizados a colocar fim a ela, no alcance de seus meios, em apoio aos princípios básicos das Nações Unidas. Entretanto, operações que possuem mandato amplo e explícito para proteção de civis devem contar com recursos específicos necessários para cumprir o mandato. (ONU, A/55/305, 2000, p. 10; tradução nossa).

O Quadro 1 a seguir apresenta as missões de paz autorizadas pelo CSNU no período 2001-2010 que contaram com mandato para proteção de civis, detalhando em quais termos este objetivo foi estabelecido.

QUADRO 1- MISSÕES DE PAZ COM MANDATO PARA PROTEGER CIVIS (2001-2010)

\begin{tabular}{|l|l|l|}
\hline \multicolumn{1}{|c|}{ Operação } & Mandato & \multicolumn{1}{c|}{ Menção à proteção de civis } \\
\hline $\begin{array}{l}\text { UNMIL } \\
\begin{array}{l}\text { Set 2003- } \\
\text { Presente } \\
\text { (Missão das }\end{array}\end{array}$ & $\begin{array}{l}\text { Resolução } \\
\mathbf{1 5 0 9} \\
\mathbf{( 2 0 0 3 )}\end{array}$ & $\begin{array}{l}\text { Proteger o pessoal, as instalações e os equipamentos da } \\
\text { ONU; garantir a segurança e liberdade de movimento de } \\
\text { seu pessoal, sem prejuízo aos esforços do governo; }\end{array}$ \\
\hline
\end{tabular}




\begin{tabular}{|c|c|c|}
\hline $\begin{array}{l}\text { NU na } \\
\text { Libéria) }\end{array}$ & & $\begin{array}{l}\text { proteger os civis sob ameaça física iminente, dentro de } \\
\text { suas capacidades. }\end{array}$ \\
\hline $\begin{array}{l}\text { UNOCI } \\
\text { Abr 2004 - } \\
\text { Presente } \\
\text { (Operação } \\
\text { das NU na } \\
\text { Costa do } \\
\text { Marfim) }\end{array}$ & $\begin{array}{l}\text { Resolução } \\
1528 \\
(2004)\end{array}$ & $\begin{array}{l}\text { Proteger o pessoal, as instalações e equipamentos das } \\
\text { Nações Unidas; garantir a segurança e liberdade de } \\
\text { movimento de seu pessoal, sem prejuízo à } \\
\text { responsabilidade do Governo de Reconciliação Nacional; } \\
\text { proteger os civis sob ameaça de violência física iminente, } \\
\text { dentro de suas capacidades e áreas de destacamento. }\end{array}$ \\
\hline $\begin{array}{l}\text { MINUSTAH } \\
\text { Jun 2004 - } \\
\text { Presente } \\
\text { (Missão de } \\
\text { Estabilização } \\
\text { das NU no } \\
\text { Haiti) }\end{array}$ & $\begin{array}{l}\text { Resolução } \\
1542 \\
(2004)\end{array}$ & $\begin{array}{l}\text { Proteger o pessoal, as instalações e equipamentos das } \\
\text { Nações Unidas; garantir a segurança e liberdade de } \\
\text { movimento de seu pessoal, levando em consideração a } \\
\text { responsabilidade primária do Governo de Transição. } \\
\text { Proteger civis sob ameaça iminente de violência física, } \\
\text { dentro de suas capacidades e áreas de destacamento, sem } \\
\text { prejuízo às responsabilidades do Governo de Transição e } \\
\text { às autoridades políticas. }\end{array}$ \\
\hline $\begin{array}{l}\text { ONUB } \\
\text { Jun } 2004 \text { - } \\
\text { dez } 2006 \\
\text { (Operação } \\
\text { das NU no } \\
\text { Burundi) }\end{array}$ & $\begin{array}{l}\text { Resolução } \\
1545 \\
(2004)\end{array}$ & $\begin{array}{l}\text { Utilizar todos os meios necessários para cumprir o } \\
\text { seguinte mandato, dentro de sua capacidade e nas áreas } \\
\text { em que as unidades armadas estão destacadas, em } \\
\text { coordenação com as comunidades humanitária e de } \\
\text { desenvolvimento: } \\
\text { - sem prejuízo à responsabilidade do Governo de } \\
\text { Transição do Burundi, proteger os civis sob ameaça } \\
\text { iminente de violência física; } \\
\text { - garantir a proteção do pessoal, dos equipamentos e das } \\
\text { instalações da ONUB, assim como a segurança e liberdade } \\
\text { de movimento do contingente da ONUB. }\end{array}$ \\
\hline $\begin{array}{l}\text { UNMIS } \\
\text { Mar 2005- } \\
\text { Jul } 2011 \\
\text { (Missão das }\end{array}$ & $\begin{array}{l}\text { Resolução } \\
1590 \\
(2005)\end{array}$ & $\begin{array}{l}\text { Tomar a ação necessária para proteger o pessoal, as } \\
\text { instalações e os equipamentos da ONU, garantir a } \\
\text { liberdade de movimento do seu pessoal e dos agentes } \\
\text { humanitários e proteger os civis sob ameaça iminente de }\end{array}$ \\
\hline
\end{tabular}




\begin{tabular}{|c|c|c|}
\hline $\begin{array}{l}\text { NU no } \\
\text { Sudão) }\end{array}$ & & $\begin{array}{l}\text { violência física, dentro das áreas de destacamento de suas } \\
\text { forças e de acordo com suas capacidades. }\end{array}$ \\
\hline $\begin{array}{l}\text { UNAMID } \\
\text { Jul 2007 - } \\
\text { Presente } \\
\text { (Operação } \\
\text { Híbrida das } \\
\text { NU/ União } \\
\text { Africana em } \\
\text { Darfur) }\end{array}$ & $\begin{array}{l}\text { Resolução } \\
1769 \\
(2007)\end{array}$ & $\begin{array}{l}\text { Tomar a ação necessária, dentro das áreas de } \\
\text { destacamento de suas forças e de acordo com suas } \\
\text { capacidades para: } \\
\text { - proteger o pessoal, as instalações e os equipamentos sob } \\
\text { mandato da ONU, garantir a segurança e liberdade de } \\
\text { movimento de seu pessoal e dos agentes humanitários; } \\
\text { - apoiar a implementação efetiva do Acordo de Paz de } \\
\text { Darfur, prevenir a eclosão de ataques armados e proteger } \\
\text { os civis, sem prejuízo à responsabilidade do governo do } \\
\text { Sudão. }\end{array}$ \\
\hline $\begin{array}{l}\text { MINURCAT } \\
\text { Set } 2007 \text { - } \\
\text { dez } 2010 \\
\text { (Missão das } \\
\text { NU na Rep. } \\
\text { Centro- } \\
\text { Africana e } \\
\text { Chade) }\end{array}$ & $\begin{array}{l}\text { Resolução } \\
1778 \\
\text { (2007) }\end{array}$ & $\begin{array}{l}\text { Autoriza a operação da União Europeia (EUFOR) a: } \\
\text { - contribuir para proteger os civis em perigo, } \\
\text { particularmente refugiados e deslocados internos; } \\
\text { - contribuir para proteger o pessoal, as instalações e os } \\
\text { equipamentos da ONU e garantir a segurança e liberdade } \\
\text { de movimento do pessoal sob mandato da ONU e } \\
\text { associados. }\end{array}$ \\
\hline $\begin{array}{l}\text { MONUSCO } \\
\text { Jul } 2010 \text { - } \\
\text { Presente } \\
\text { (Missão de } \\
\text { Estabilização } \\
\text { das NU na } \\
\text { República } \\
\text { Democrática } \\
\text { do Congo) }\end{array}$ & $\begin{array}{l}\text { Resolução } \\
1925 \\
(2010)\end{array}$ & $\begin{array}{l}\text { Decide que a configuração da MONUSCO deve se basear na } \\
\text { evolução dos acontecimentos locais e das conquistas dos } \\
\text { seguintes objetivos por parte do governo do país e da } \\
\text { missão da ONU: } \\
\text { - maior capacidade do governo da Rep. Dem. Congo para } \\
\text { efetivamente proteger sua população, por meio do } \\
\text { estabelecimento de forças de segurança sustentáveis que } \\
\text { progressivamente assumam as responsabilidades de } \\
\text { segurança da MONUSCO; }\end{array}$ \\
\hline
\end{tabular}




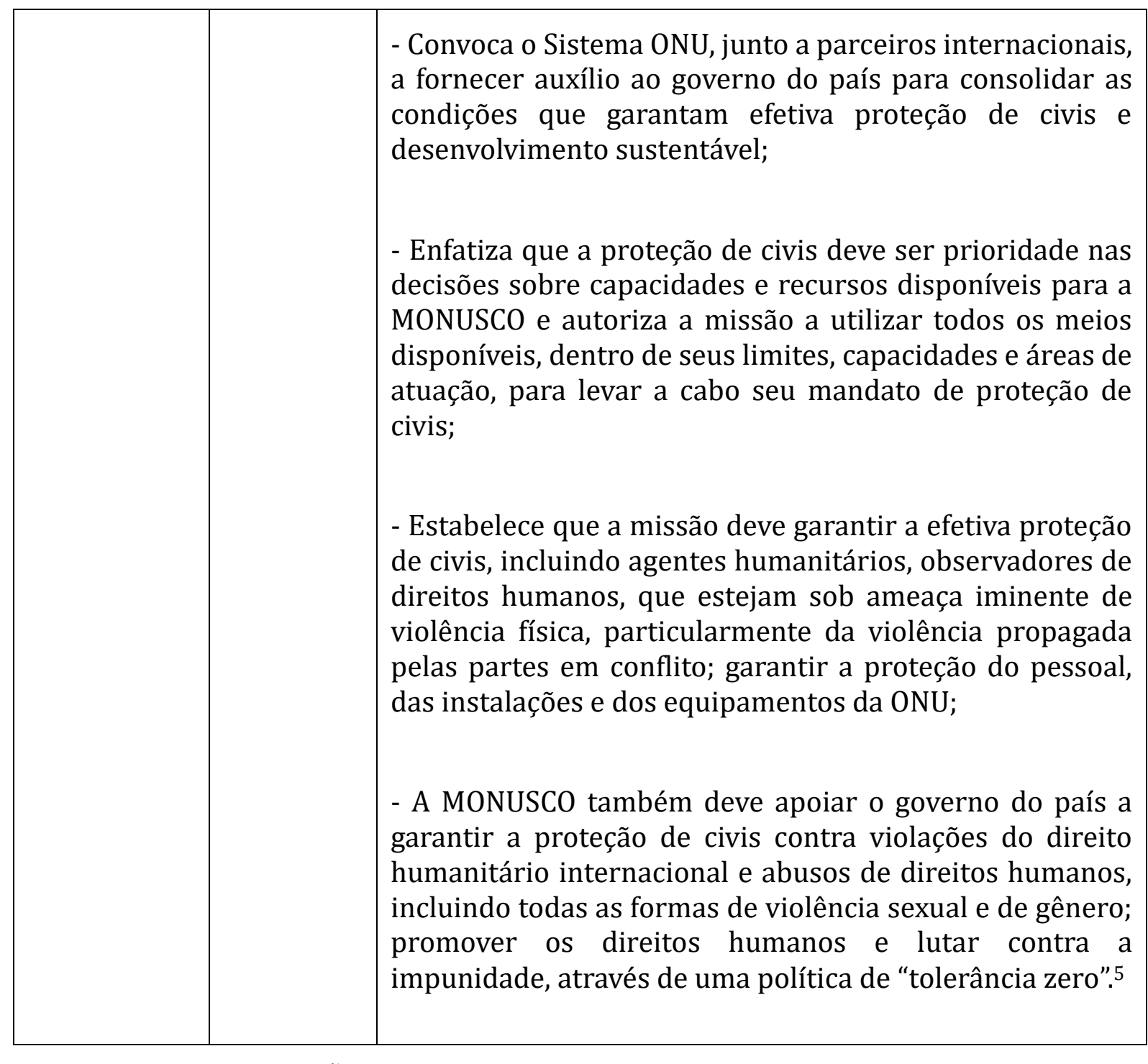

Organização: BIGATÃO, J. P. Fonte: DPKO. Disponível em: http://www.un.org/Depts/dpko/dpko/. Acesso em 15/02/2015.

Considerando que no período de 2001 a 2010 o CSNU autorizou 10 novas operações de paz, verifica-se no Quadro 1 que oito delas receberam mandato explícito para proteger civis e foram respaldadas pelo Capítulo VII da Carta da ONU. As exceções foram as missões no Timor Leste (UNMISET e UNMIT), que possuíam perfil de apoio à administração civil do país e contingente militar gradativamente reduzido.

\footnotetext{
5 Em março de 2013, tendo em vista a deterioração da segurança na região oriental da República Democrática do Congo, especialmente nas províncias de Oriental, Kivu do Norte e do Sul, o CSNU autorizou a Brigada de Intervenção por um ano, renovada até 31 de março de 2015. Constituída de três batalhões de infantaria, um de artilharia e uma força especial, a Brigada de Intervenção recebeu um mandato inédito nas missões de paz da $\mathrm{ONU}$, sendo autorizada a neutralizar grupos armados com a finalidade de estabilizar a violência que ameaçava as autoridades estatais e a população civil. Para mais informações, consultar goo.gl/amG5wP. Acesso em 02/02/2015.
} 
Ao longo da década de 2000, é possível observar que os mandatos para proteção de civis, todos eles incluindo a proteção dos profissionais da ONU, tornaram-se cada vez mais específicos. No entanto, a expressão "sem prejuízo à responsabilidade do governo" pode ser entendida como um condicionante imposto pela autoridade do país que recebeu a missão para que aceitasse este tipo de mandato.

Ban Ki-moon (2011) ressaltou em seu discurso na Universidade de Oxford que os governos do Chade, do Sudão e da República Democrática do Congo, em alguns momentos, interpretaram a prática da proteção de civis como uma tarefa que extrapolava o mandato da $\mathrm{ONU}$, apresentando restrições quanto à implementação da norma, embora tivessem consentido a missão ${ }^{6}$.

Na avaliação de Bellamy e Williams (2011), os mandatos robustos da década de 2000, respaldados pelo Capítulo VII e investidos da responsabilidade de proteção de civis, representaram grandes avanços para as missões de paz e foram aprovados com o consentimento das partes em conflito. Contudo, conforme destaca Johnstone (2011), muitos consentimentos formais garantidos ao CSNU adquiriram outro significado na prática das missões. No caso do Sudão, por exemplo, o consentimento dado à ONU por meio do Acordo de Paz de Darfur (2006) rapidamente tornou-se obsoleto, pois o governo sudanês recusou-se a cooperar com a UNAMID. Em Serra Leoa, a liberdade de movimento dos integrantes da operação de paz era tão restrita que os peacekeepers tornarem-se praticamente reféns do governo local, o qual controlava todos os deslocamentos das tropas da ONU.

Ao analisar a missão de paz da ONU em Darfur, Sloan (2014) destacou que o princípio do consentimento e a necessidade de manter boas relações com o governo sudanês limitava os peacekeepers a uma postura não-confrontativa que prejudicava a consecução do mandato, por exemplo, dificultando as respostas aos ataques contra civis perpetrados por forças do próprio governo. 0 caso de Darfur corrobora o argumento de Bellamy e Williams, segundo os quais

$\mathrm{Na}$ prática, as ressalvas e os problemas relacionados com o consentimento resultaram em operações de paz que empregaram a força para proteger civis com pouca frequência e, na maioria dos casos, apenas contra atores não-estatais

\footnotetext{
${ }^{6}$ Em 2011, ao tratar da situação na Líbia, o CSNU pela primeira vez autorizou um mandato coercitivo, com o uso da força, para a proteção de civis, sem contar o consentimento do governo central. Porém, a aplicação da força ficou a cargo da OTAN, e não de uma tropa multinacional sob comando da ONU. Consultar Resolução 1973, 2011. Disponível em: goo.gl/EBw2Ts. Acesso em 25/11/2014.
} 
(apesar do fato de que as forças do governo eram muitas vezes igualmente culpadas). (BELLAMY; WILLIAMS, 2011, p. 828; tradução nossa).

Hultman, Kathman e Shannon (2013) ressaltaram que, apesar de operar com algumas limitações, as missões da ONU, que contam com mandato adequado, podem contribuir positivamente para diminuir o número de mortes de civis. Os pesquisadores avaliaram tal efeito a partir da análise de dados mensais sobre o número e o tipo de peacekeepers (militares, policiais ou observadores) nas missões da ONU e o número de mortes de civis em conflitos armados na África Subsaariana, no período de 1991 a 20087. Os resultados mostraram que, quanto maior o contingente de forças militares e policiais nas missões da ONU com mandato robusto $^{8}$, menor a quantidade de baixas civis. $\mathrm{Na}$ direção inversa, quando se tratava do envio de observadores militares (que, diferente das forças militares e policiais, não podem utilizar armamento) não houve impacto positivo na diminuição da morte de civis, sendo inclusive constatado um aumento das vítimas.

Segundo os autores, as tropas militares da ONU são importantes porque funcionam como elemento de separação entre os grupos combatentes e ocupam espaços (zonas tampão) que poderiam ser utilizados para atingir civis. Os estudos mostraram, também, que os policiais contribuíram para o patrulhamento das comunidades, reduzindo as oportunidades para que os grupos em oposição cometessem atrocidades contra os civis. A pesquisa apontou que o envio de observadores militares não é adequado para o objetivo de proteger civis, pois eles não possuem os meios para cumprir tal tarefa. (HULTMAN; KATHMAN; SHANNON, 2013).

Johnstone (2011) avaliou que os dilemas presentes nas discussões a respeito dos limites das operações de paz da ONU frente ao princípio do consentimento remetem a uma questão mais abrangente sobre a disposição das elites locais dos países em conflito para aceitar a ingerência de atores externos, mesmo que estes se comprometam com o fortalecimento da capacidade estatal e com a provisão de assistência para o desenvolvimento. Muitas vezes, a necessidade de restabelecer a soberania sobre o

\footnotetext{
7 Os autores utilizam a base de dados do Uppsala Conflict Data Program/ Peace Research Institute, Oslo (UCDP/PRIO) para informações sobre conflitos, o UCDP Georeferenced Events Dataset para os dados sobre mortes de civis e as informações do DPKO para coletar os contingentes das missões.

8 Na concepção de Hultman, Kathman e Shannon (2013), a robustez do mandato está diretamente relacionada à quantidade de peacekeepers que compõe o contingente da missão e à autorização explícita para a proteção de civis.
} 
território e controlar grupos armados levam essas elites a aceitarem a presença dos atores externos; porém, quando estes últimos desafiam as formas de governo locais, por exemplo, questionando as ações das forças do governo contra a população frente aos princípios dos direitos humanos, o risco de perder a cooperação daqueles que consentiram a missão torna-se muito alto.

O caso do Sudão ilustra o argumento, pois o presidente do país, Omar al-Bashir, inicialmente cooperou com a UNAMID em virtude de pressões internacionais que indicavam seu possível indiciamento pelo Tribunal Penal Internacional por crimes de guerra e crimes contra a humanidade, dadas as atrocidades cometidas contra civis, principalmente na região de Darfur. No entanto, após concorrer e vencer as eleições de 2010, Bashir passou a reprovar algumas ações da UNAMID, por exemplo, determinando que o governo sudanês fosse informado de todas as movimentações dos peacekeepers pelas estradas e cidades de sua área de atuação e que as forças do governo inspecionassem suas bagagens. (JOHNSTONE, 2011).

Desta forma, nota-se que existem efeitos positivos, mas também entraves na implementação da norma da proteção de civis. Os mandatos robustos e a provisão de contingentes adequados e em número suficiente indicam maiores possibilidades para que os peacekeepers atinjam seus objetivos; porém, o princípio do consentimento limita a aplicação da norma a determinadas circunstâncias.

\section{CONSIDERAÇÕES FINAIS}

Este artigo avaliou que as operações de paz autorizadas pelo CSNU na década que sucedeu a publicação do Relatório Brahimi (2000) possuíam características consonantes com as recomendações deste documento, especialmente no que diz respeito à autorização de mandatos mais robustos e voltados à proteção de civis. Em comparação com as missões da década de 1990, de fato os mandatos confiaram aos peacekeepers uma abordagem mais ampla para evitar que eles testemunhassem atrocidades sem possuir o mandato para reagir.

De todas as missões aprovadas no período 2001-2010, apenas duas não foram conferidas com a função de proteger civis. Porém, o Capítulo VII não significou a transformação de uma missão de paz em uma operação de guerra, dados os limites 
impostos às ações dos peacekeepers, que fizeram com que muitos dos dilemas enfrentados na implementação das missões fossem semelhantes àqueles verificados na década de 1990, inseridos na problemática que contrapõe as missões multidimensionais com mandatos robustos, o princípio do consentimento das partes e as limitações quanto ao uso da força por parte dos peacekeepers. Desta forma, é possível afirmar que a nova abordagem para a proteção de civis não alterou a essência das operações de paz.

\section{REFERÊNCIAS BIBLIOGRÁFICAS}

A/47/277, 1992. An Agenda for Peace: Preventive diplomacy, peacemaking and peacekeeping.

A/50/60, 1995. Supplement to an Agenda for Peace.

A/54/549, 1999. The Fall of Srebrenica. Report of the Secretary-General pursuant to General Assembly Resolution 53/35. Disponível em: goo.gl/CSg8r4. Acesso em $12 / 08 / 2015$.

A/55/305, 2000. Report of the Panel on United Nations Peace Operations. Disponível em <http://www.un.org/documents/ga/docs/55/a55305.pdf> Acesso em 03/09/2015.

A/59/565, 2004. Follow-up to the outcome of the Millennium Summit. A more secure world: our shared responsibility. Report of the High-level Panel on Threats, Challenges and Change. Disponível em: goo.gl/lpGIFy. Acesso em 29/07/2014.

A/63/677, 2009. Implementing the responsibility to protect. Report of the Secretary General. Disponível em: goo.gl/fqox4H. Acesso em 01/03/2016.

A/RES/60/1, 2005 World Summit Outcome. Disponível em <http://mdgs.un.org/unsd/mdg/Resources/Attach/Indicators/ares60_1_2005sum mit_eng.pdf> Acesso em 23/11/2014.

BELLAMY, A. J.; WILLIANS, P.; GRIFFIN, S. Understanding Peacekeeping. Cambridge: Polity Press, 2004.

BELLAMY, A. J.; WILLIAMS, P. The new politics of protection? Côte d'Ivoire, Libya and the responsibility to protect, International Affairs, v. 87, n. 4, 2011, p. 825-850

DPKO. Department of Peacekeeping Operations. Disponível em <http://www.un.org/en/peacekeeping/about/dpko/> Acesso em 26/02/2016.

EVANS, G. Security Threats, Challenges and Change: The UN Secretary General's High Level Panel. International Crisis Group, 2004. 2012.

Responding to atrocities: the new geopolitics of intervention. SIPRI Yearbook

FETHERSTONE, A. B. Peacekeeping, Conflict Resolution and Peacebuilding: A Reconsideration of Theoretical Frameworks. International Peacekeeping, v. 7, n.1, p. 190-218, 2000.

FINDLAY, T. The use of force in UN peace operations. Oxford: Oxford University Press, 2002.

Conjuntura Global, vol. 5 n. 3, set./dez, 2016, p. 460 - 483 
FOLEY, C. Avanços normativos sobre a proteção de civis em conflitos armados. IN: HAMMAN, E. P.; MUGGAH, R. A implementação da responsabilidade de proteger: novos rumos para a paz e a segurança internacional? Brasília: Instituto Igarapé, 2013. (p. 10-18)

FRÉCHETTE, L. UN Peacekeeping: 20 years of reform. CIGI Papers, n. 02, April 2012.

Global Centre for the Responsibility to Protect, 2012. The Relationship between the Responsibility to Protect and the Protection of Civilians in Armed Conflict. Disponível em <https://www.ciaonet.org/attachments/23897/uploads> Acesso em 01/03/2016.

GREY, C. Peacekeeping After the Brahimi Report: Is There a Crisis of Credibility for the UN? Journal of Conflict \& Security Law, v. 6, n.2, p. 267-288, 2001.

HULTMAN, L. UN Peace Operations and Protection of Civilians: Cheap Talk or Norm Implementation? Journal of Peace Research, v. 50, n. 1, p 59-73, 2013.

. Robust Peacekeeping: a desirable development? E-International Relations, set. 2014. Disponível em <http://www.e-ir.info/2014/09/02/robust-peacekeeping-adesirable-development/> Acesso em 24/11/2014.

; KATHMAN, J.; SHANNON, M. United Nations Peacekeeping and Civilian Protection in Civil War. American Journal of Political Science, v. 57, n. 4, p. 875-891, out. 2013.

JOHNSTONE, I. Managing consent in contemporary peacekeeping operations, International Peacekeeping, v.18, n. 2, p. 168-82, 2011.

KI-MOON, B. Human Protection and the $21^{\text {st }}$ century United Nations, Cyril Foster Lecture, Oxford University, 2011.

MALONE, D. M.; THAKUR, Ramesh. UN Peacekeeping: lessons learned? Global Governance, v. 7, n. 1, p. 11-17, jan/march. 2001.

Report of the International Commission on Intervention and State Sovereignty: "The Responsibility To Protect", December 2001. Disponível em <http://responsibilitytoprotect.org/ICISS\%20Report.pdf> Acesso em 14/02/2016.

S/1999/1257, 1999. The Report of the Independent Inquiry into the Actions of the United Nations during the 1994 Genocide in Rwanda. Disponível em <http://www.un.org/en/ga/search/view_doc.asp?symbol=S/1999/1257> Acesso em $12 / 08 / 2015$.

S/RES/1270, 1999. United Nations Security Council, 22 October 1999. Disponível em <http://www.un.org/en/ga/search/view_doc.asp?symbol=S/RES/1270(1999)> Acesso em 24/11/2014.

S/RES/1318, 2000. United Nations Security Council. Declaration on Ensuring an Effective Role for the Security Council in the Maintenance of International Peace and Security, Particularly in Africa. Disponível em: goo.gl/jPsZGs. Acesso em 27/02/2016.

S/RES/1674, 2006. United Nations Security Council, 28 April 2006. Disponível em <http://www.un.org/en/ga/search/view_doc.asp?symbol=S/RES/1674(2006)> Acesso em 24/11/2014. 
S/RES/1894, 2009. United Nations Security Council, 11 November 2009. Disponível em <http://www.un.org/en/ga/search/view_doc.asp?symbol=S/RES/1894(2009)> Acesso em 24/11/2014.

SLOAN, J. UN Peacekeeping in Darfur: A 'Quagmire' That We Cannot Accept. EInternational Relations, june 2014.

ST-PIERRE, K. Then \& Now: Understanding the Spectrum of Complex Peace Operations. Pearson Peacekeeping Centre, 2008.

UNITED NATIONS PEACEKEEPING OPERATIONS. Principles and Guidelines, 2008. Disponível em <http://pbpu.unlb.org/pbps/Library/Capstone_Doctrine_ENG.pdf> Acesso em 13/08/2014. 